The Journal of Laryngology \& Otology

http://journals.cambridge.org/JLO

Additional services for The Journal of Laryngology \& Otology:

Email alerts: $\underline{\text { Click here }}$

Subscriptions: $\underline{\text { Click here }}$

Commercial reprints: $\underline{\text { Click here }}$

Terms of use : $\underline{\text { Click here }}$

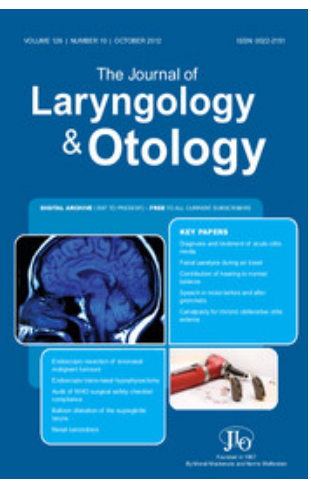

\title{
Misdiagnosis of hearing loss due to ear canal collapse: a report of two cases
}

Cliodna F. O Mahoney and Linda M. Luxon

The Journal of Laryngology \& Otology / Volume 110 / Issue 06 / June 1996, pp 561 - 566

DOI: 10.1017/S0022215100134279, Published online: 29 June 2007

Link to this article: http://journals.cambridge.org/abstract_S0022215100134279

How to cite this article:

Cliodna F. O Mahoney and Linda M. Luxon (1996). Misdiagnosis of hearing loss due to ear canal collapse: a report of two cases. The Journal of Laryngology \& Otology, 110, pp 561-566 doi:10.1017/S0022215100134279

Request Permissions : $\underline{\text { Click here }}$ 


\title{
Clinical Records
}

\section{Misdiagnosis of hearing loss due to ear canal collapse: a report of two cases}

\author{
Cliodna F. O Mahoney, Linda M. Luxon
}

\begin{abstract}
Collapse of the external auditory meatus during audiometry can lead to spuriously increased hearing thresholds being obtained, particularly at high frequencies, and may simulate conditions such as noise-induced hearing loss, presbyacusis and retrocochlear pathology. Consequently, inappropriate investigations and management may be undertaken. Two patients with elevated thresholds secondary to ear canal collapse are described. The implications of initially failing to identify the true nature of their 'hearing losses' are highlighted and strategies to avoid such pitfalls are discussed.
\end{abstract}

Key words: Ear canal; Audiometry, complications

\section{Introduction}

Air:bone gaps suggesting a conductive hearing loss affecting predominantly the high frequencies have previously been described, and aetiologies, including cerumen in the ear canal, healed tympanic membrane perforations and partial ossicular disruption, discussed (Ventry et al., 1961; Hildyard and Valentine, 1962; Chandler, 1964; Coles, 1967; Bess, 1971; Mustain and Hasseltine, 1981; Marshall et al., 1983; Randolph and Schow, 1983). An important cause of such conductive losses to exclude is the spurious air:bone gap associated with ear canal collapse due to pressure of the earphone on the pinna during audiometry. This condition was first described in 1961 by Ventry et al., when they noted a 15-30 dB improvement in the air conduction thresholds at $250 \mathrm{~Hz}, 500 \mathrm{~Hz}, 1 \mathrm{kHz}$ and $2 \mathrm{kHz}$, of two patients, when the ear canals were held patent during audiometry by plastic inserts.

Reports since then have suggested that the elderly population are more susceptible to such ear canal collapse, thought to be due to degenerative changes taking place in the elastic tissue of the dermis of the external ear (Dick, 1947; Ma and Cowdry, 1950). Randolph and Schow (1983) reported its incidence to be as high as 36 per cent in the age-group between 60 and 79 years. However all age groups can be affected. Anatomical abnormalities of the outer ear, either congenital (i.e. the 'lop ears' described by Ventry et al., 1961) or traumatic (Coles, 1967) may be predisposing factors in younger patients. Hildyard and Valentine (1962) reported 48 cases of canal collapse representing four per cent of their total clinical population (aged eight to 76 years). The majority of patients were over 65 years, but five were under 30 years. The average improvement in thresholds when using a stopple was 9.6 $\mathrm{dB}$ for frequencies between $500 \mathrm{~Hz}$ and $4 \mathrm{kHz}$. However the effect was most marked at $2 \mathrm{kHz}$, with a typical reduction in threshold of $14.6 \mathrm{~dB}$ at this frequency. Creston (1965) found impaired air conduction thresholds attributable to ear canal collapse, provoked by pressure from audiometric earphones, in 3.8 per cent of 282 children aged between six and nine years. Penrod (1981) described improvement in air conduction thresholds of 25-35 dB at all octave frequencies between $250 \mathrm{~Hz}$ and $4 \mathrm{kHz}$, with an earmould insert in situ to keep the canal patent. In Coles' (1967) study of 1,633 17-25 year olds, elevated thresholds of greater than $20 \mathrm{~dB}$ due to ear canal closure occurred in only 0.1 per cent (two patients) of the group. One of these patients, a 19-year-old man, showed an audiometric pattern suggestive of noise-induced hearing loss, but on insertion of a tubular insert, improvement in thresholds of $10 \mathrm{~dB}$ at $500 \mathrm{~Hz}, 20 \mathrm{~dB}$ at $1 \mathrm{kHz}$ and $2 \mathrm{kHz}, 40 \mathrm{~dB}$ at $4 \mathrm{kHz}$ and $60 \mathrm{~dB}$ at $6 \mathrm{kHz}$ occurred.

Other reports have confirmed that air:bone gaps due to ear canal closure, may be seen across the frequency range, although they are usually more pronounced at the higher frequencies, particularly at $2 \mathrm{kHz}$ and $3 \mathrm{kHz}$ (Chandler, 1964; Creston and Tice, 1964; Marshall and Grossman, 1982). Values for attenuation of the air conduction threshold due to canal closure range between $5 \mathrm{~dB}$ and $40 \mathrm{~dB}$.

Various strategies have been proposed for the correction of ear canal collapse, including use of circumaural earphones, which do not press on the pinna, and the insertion of tubes, specula, earmoulds etc. into the ear canal in order to keep it patent. The introduction of a stopple/speculum into the ear canal may alter the resonant characteristics of the canal and thus lead to either improved or impaired threshold values. Chaiklin and McClellan (1971) point out that although the use of such inserts is effective in many individuals with canal collapse, the introduction of inserts into a normal canal can lead to a decrease in hearing sensitivity, particularly at high frequencies. These are also the frequencies most affected 
by canal collapse and thus limit the enhancing effect of the procedure. Likewise, Bryde and Feldman (1980) reported on average a $5 \mathrm{~dB}$ decrease in sensitivity at $2 \mathrm{kHz}$ and a mean decrease of $10 \mathrm{~dB}$ from $3 \mathrm{kHz}$ to $8 \mathrm{kHz}$ in 50 per cent of a group of 21 normally hearing subjects with noncollapsing canals when an impedance probe tip was inserted into the canal.

\section{Cases}

The two cases reported below demonstrate the erroneous thresholds which may be obtained if ear canal collapse occurs during audiometry, and highlight the potential for subsequent misdiagnoses and inappropriate investigation/management if the clinician/audologist does not take precautions to avoid such inaccuracies.

\section{Patient 1}

This patient presented at the age of 62 years with a twenty-year history of bilateral tinnitus precipitated by stress related to a near-miss serious road traffic accident. Initially tinnitus was not intrusive, but for one year prior to consultation it had become more troublesome following the death of her husband. In addition, an influenza-like illness three months before her clinic appointment further exacerbated the tinnitus in the left ear.

She had no past history of ear disease or head injury and no ototoxic drug, gunfire or other noise exposure. There was no family history of hearing loss, dizziness or tinnitus.

Examination was normal apart from the Weber test localizing to the right. In retrospect her left ear canal was thought to be narrow but this had not been particularly noted initially. Bekesey audiometry showed a left-sided sloping loss in the high frequencies, thresholds being $15-30 \mathrm{~dB}$ greater than on the right (Figure 1). Tympanometry and stapedial reflexes were normal bilaterally with no reflex decay. Caloric testing showed a 30 per cent left canal paresis with a 20 per cent directional preponderance to the right. Tomograms of her internal acoustic meati were normal as was auditory evoked brainstem response testing. On subsequent follow-up, Bekesey audiometry showed a deterioration in her low frequency thresholds on the left (Figure 2), although high frequency thresholds were similar. MRI scanning of the brain - both axial and coronal - showed no abnormality. One year after her initial visit, pure tone audiometry - both air conduction and bone conduction - was performed and showed normal thresholds for her age on the right and a conductive loss on

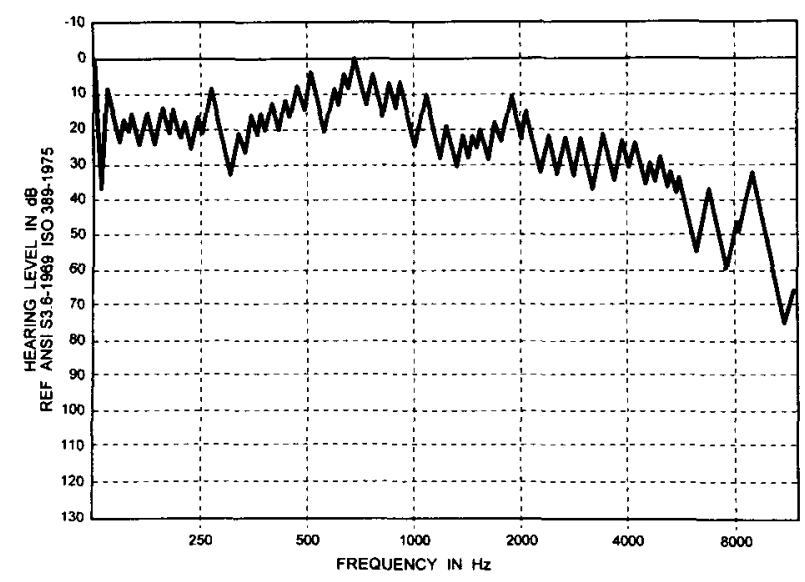

FIG. 1

Left Bekesey audiogram of Patient $I$ showing sloping high frequency hearing loss. Thresholds on the right were normal. the left (Figure 3). An air:bone gap of $20 \mathrm{~dB}, 10 \mathrm{~dB}$, and 30 $\mathrm{dB}$ was shown at $1 \mathrm{kHz}, 2 \mathrm{kHz}$ and $4 \mathrm{kHz}$ respectively, again despite normal tympanometry and stapedial reflexes. As there was no explanation for this apparent conductive hearing loss, pure tone audiometry was repeated, this time with an auriscope speculum in situ on the left side to ensure patency of the ear canal. The results are shown in Figure 3. The left sided thresholds were then normal and the air:bone gap was closed at all frequencies. Further review eight months later, with a speculum in the left ear canal, confirmed the normal thresholds in both ears.

It was therefore concluded that this patient had no pathology in the auditory system, and that her tinnitus was related to stress, due to the near-miss accident in the first place and subsequently exacerbated by the death of her husband and the influenza-like illness. The mild left canal paresis was possibly erroneous and due to poor irrigation because of the narrow external meatus, or may represent a true canal paresis, due to peripheral vestibular pathology secondary to the viral-type illness.

\section{Patient 2}

A 42-year-old man was initially seen elsewhere after a road traffic accident, in which he was knocked off his bicycle and rendered unconscious, with bleeding from his left ear. Initially he complained of left-sided hearing loss, attributed to blood in the external auditory meatus, and dizziness. Three months after the accident, the dizziness had resolved and his hearing was subjectively normal. However, during subsequent assessment of his hearing for a claim related to the accident, he was told that he had a hearing loss, typical of occupational noise exposure. He had worked in a variety of labouring jobs over a period of 16 years, which had included exposure to considerable machinery noise, particularly pneumatic drills, without ear protection. However he reported that he had always been able to carry on conversations at a distance of three feet. In childhood, he had undergone bilateral mastoid operations, with no subsequent ear problems. There was no history of ototoxic drug or gunfire exposure.

Four years after the accident he was first seen by one of the authors (LML). Apart from bilateral post-aural incisions otoscopy was normal. The Rinne test was positive bilaterally but the Weber test localized to the right. Pure tone audiometry (Figure 4) showed significant air:bone gaps at $4 \mathrm{kHz}$ and $6 \mathrm{kHz}$ on the right, although with air conduction thresholds within the normal range for his age

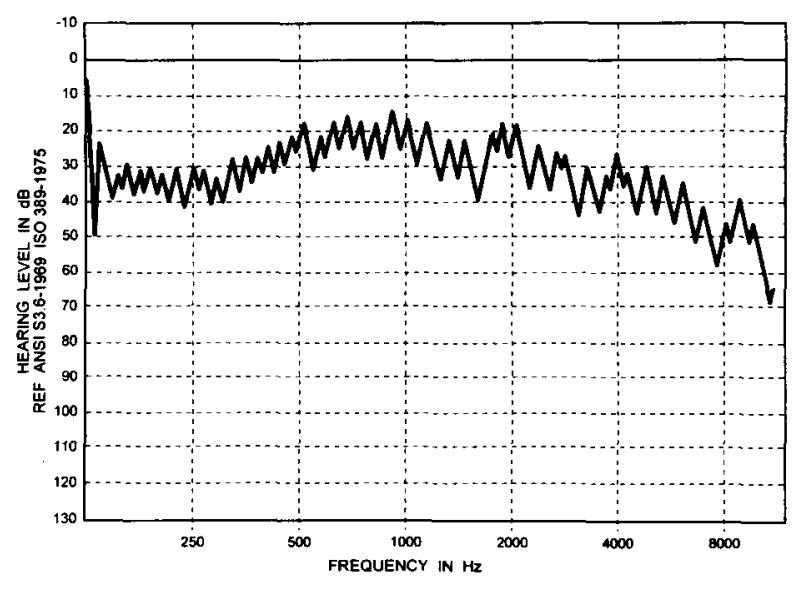

Fig. 2

Repeat left Bekesey audiogram on Patient 1 . High frequency thresholds are similar to Figure 1, but low frequency thresholds have deteriorated. 

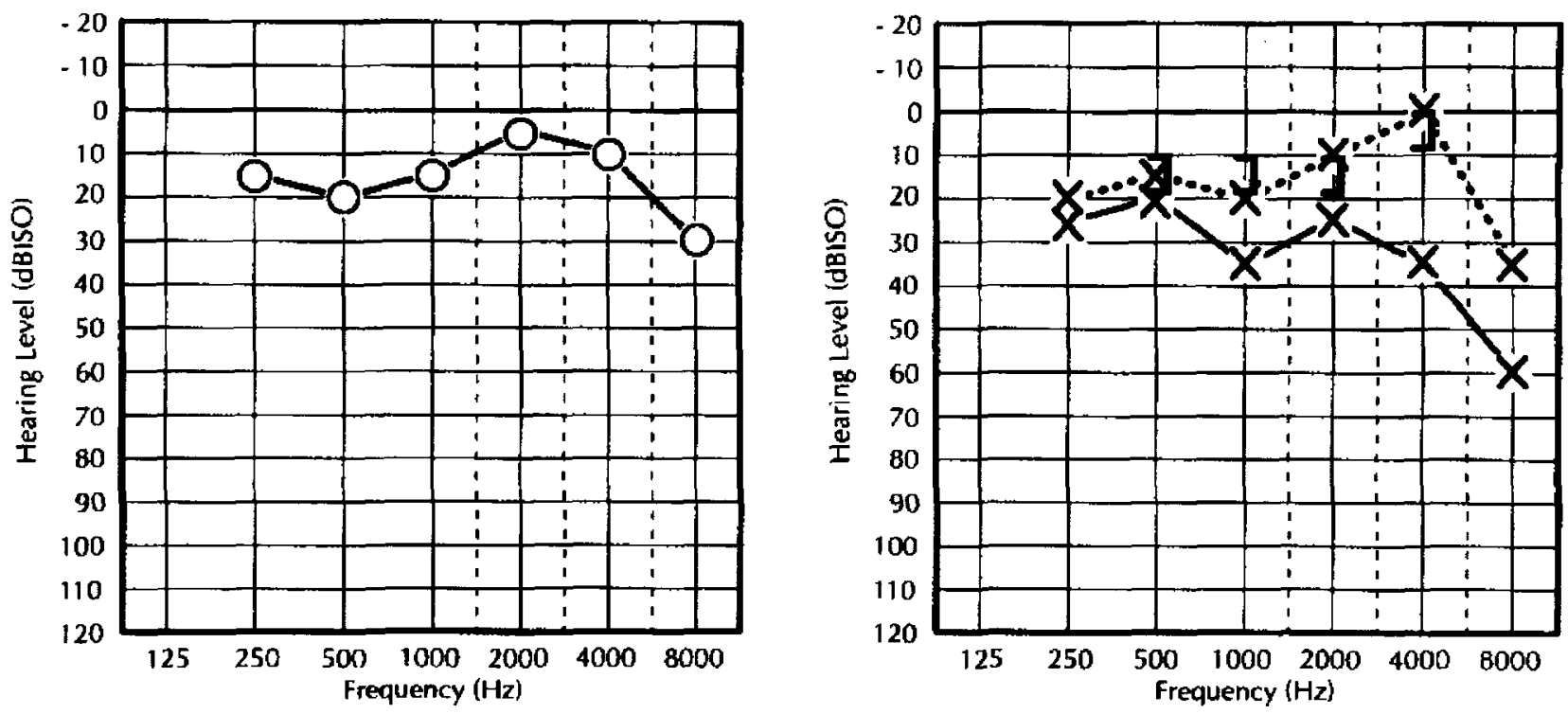

Fig. 3

Pure tone audiogram before (continuous line) and after (dotted line) insertion of speculum in Patient 1 . Note air:bone gap at $1 \mathrm{kHz}$ and $4 \mathrm{kHz}$.

(Shipton, 1979). On the left a clearly abnormal air conduction threshold of $45 \mathrm{~dB}$ was obtained at $4 \mathrm{kHz}$ with an air:bone gap of $25 \mathrm{~dB}$. Significant air:bone gaps were also recorded at $250 \mathrm{~Hz}, 1 \mathrm{kHz}$ and $6 \mathrm{kHz}$ on the left side. Thresholds at $1 \mathrm{kHz}$ and $4 \mathrm{kHz}$ bilaterally were confirmed by cortical evoked audiometry. Tympanometry and stapedial reflexes, both ipsilateral and contralateral, were normal bilaterally. In view of the normal tympanometry and stapedial reflexes despite an apparent conductive loss repeat audiometry with an auriscope speculum in situ was carried out and the results are shown in Figure 5. The $4 \mathrm{kHz}$ notch originally seen on the left side disappeared with no air:bone gap and similarly the air:bone gap at $4 \mathrm{kHz}$ on the right resolved. There was no change in bone conduction thresholds. His hearing is normal for his age (Shipton, 1979). The persistence of the air:bone gap at $250 \mathrm{~Hz}$ and $1 \mathrm{kHz}$ on the left is probably due to his previous mastoid surgery. The slightly worse

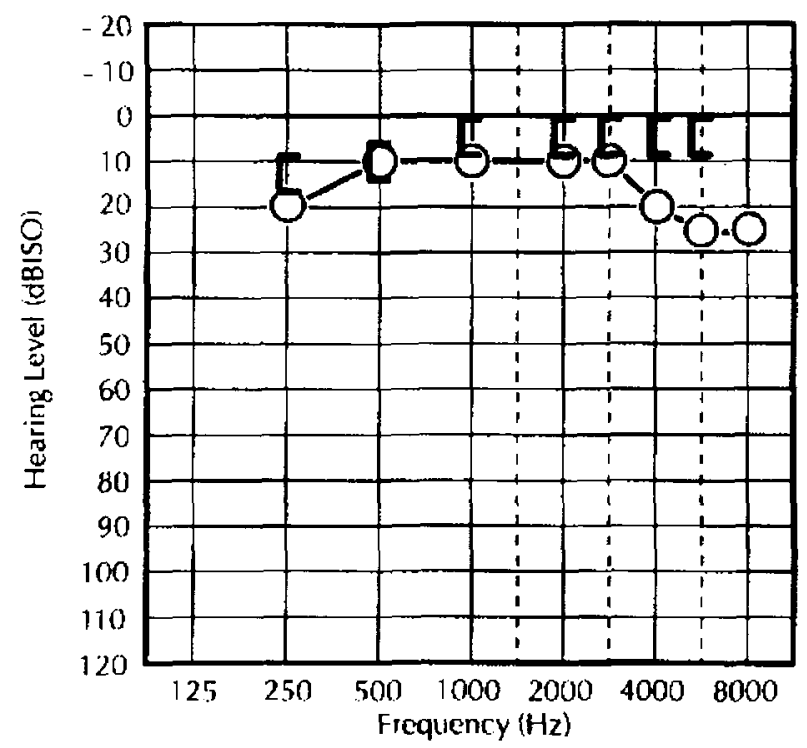

hearing on the left as compared to the right at $4 \mathrm{kHz}$ may be related to his head injury, particularly in view of his history of dizziness suggestive of labyrinthine dysfunction. There is, however, no audiometric evidence that this patient has noise induced hearing loss.

\section{Effect of insertion of speculum}

In order to further evaluate the effect of introducing into the ear canal a speculum of the type reported in the two patients above, 10 patients who were undergoing routine audiovestibular testing for the investigation of hearing loss, but with no evidence of ear canal collapse, underwent pure tone audiograms with and without a speculum in situ. Improvements in threshold with a speculum in situ were designated as positive values, while deterioration in threshold were designated by a negative value.

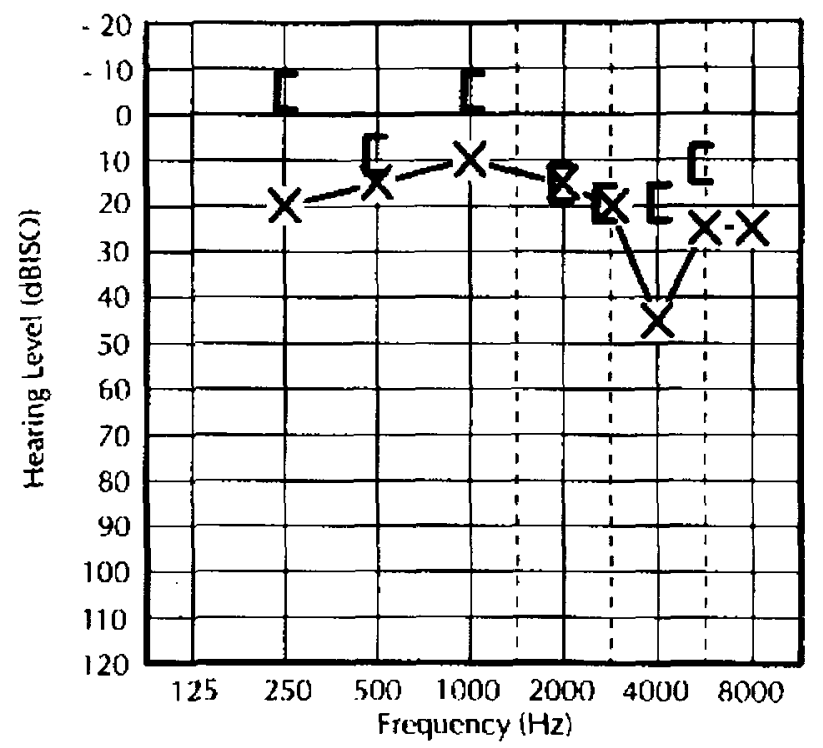

FIG. 4

Pure tone audiogram in Patient 2 before insertion of speculum. Air conduction thresholds suggest noise-induced hearing loss. Note significant air:bone gap at $4 \mathrm{kHz}$ and $6 \mathrm{kHz}$ bilaterally, and additionally at $250 \mathrm{~Hz}$ and $1 \mathrm{kHz}$ on the left. 

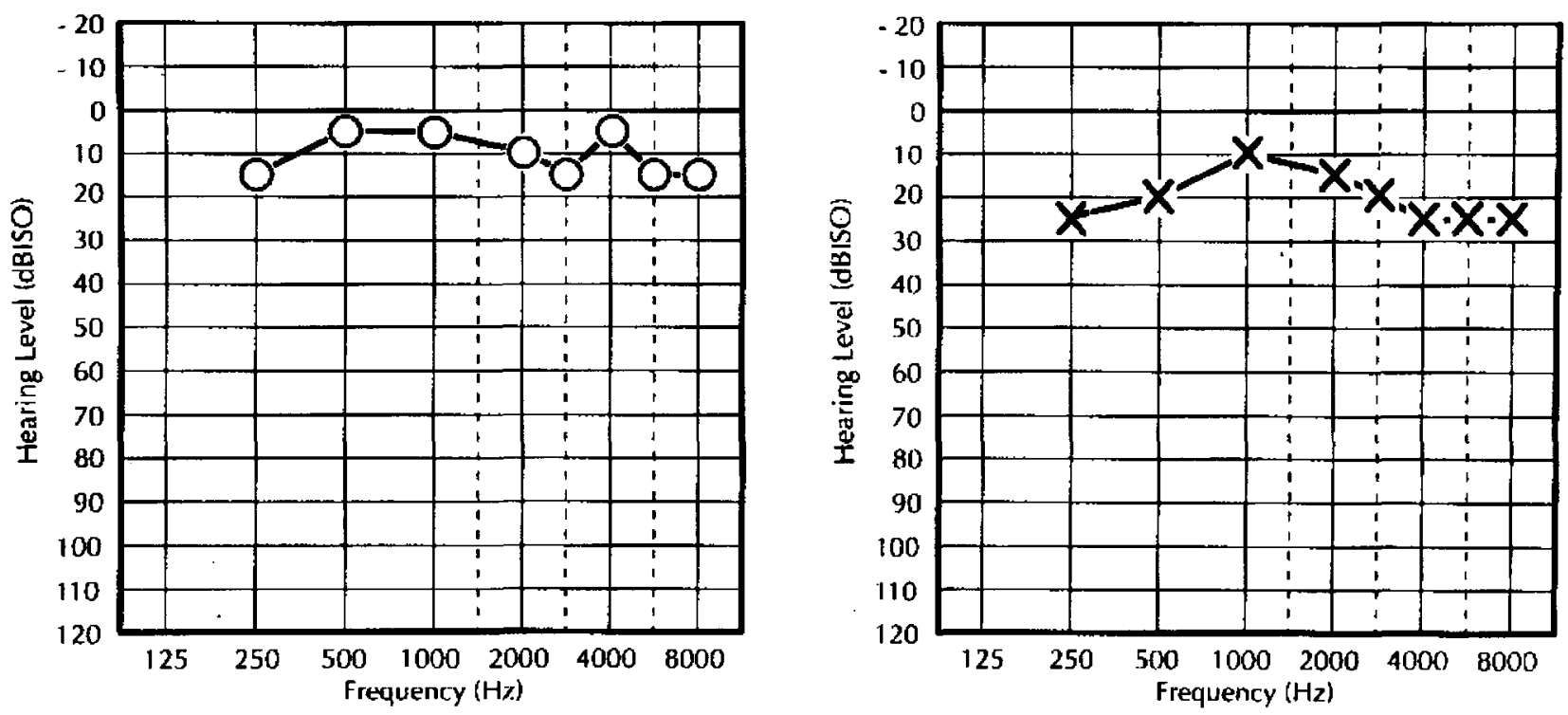

FIG. 5

Pure tone audiogram (Patient 2), after insertion of speculum, showing improvement in air conduction thresholds of $20 \mathrm{~dB}$ at $4 \mathrm{kHz}$ on left and $15 \mathrm{~dB}$ on right.

\section{Results}

At the eight frequencies tested in each ear between 250 $\mathrm{Hz}$ and $8 \mathrm{kHz}$ (Table I), 88 per cent of the 160 threshold values were identical or within a $5 \mathrm{~dB}$ discrepancy (which was considered to be within experimental error for the procedure) whether or not the speculum was in situ. In seven per cent a $\pm 10 \mathrm{~dB}$ discrepancy was noted, but where more than one frequency was affected in the same ear the discrepancy never occurred at two adjacent frequencies. In four per cent (i.e. six ears) there was a $\pm 15 \mathrm{~dB}$ discrepancy, but never at more than one frequency in any one ear.

At each frequency, there was a fairly even distribution of identical thresholds, positive and negative discrepancies, with the exception of $250 \mathrm{~Hz}$ and $8 \mathrm{kHz}$. At these two frequencies, when the speculum was in situ a poorer threshold was commonly observed ( 78 per cent and 82 per cent respectively). The average discrepancy at each frequency is shown in Table $I$.

\section{Discussion}

Over the first three clinic visits, audiometric tests on Patient 1 without a speculum, consistently showed high frequency hearing loss on the left side initially presumed to be sensorineural, but later shown to be associated with an air:bone gap. On her second and third visits she had in addition, a low frequency loss. Repeat testing during her third visit, with the speculum in situ revealed normal air conduction and bone conduction thresholds - confirmed again eight months later. Likewise Patient 2's audiogram reverted to normal when an insert was in place.

Causes of significant air:bone gaps, but with preservation of stapedial reflexes include, partial ossicular disruption (Klockhoff, 1961; Anderson and Barr, 1971; Mustain and Hasseltine, 1981) cerumen in the ear canals, healed tympanic membrane perforation (Marshall et al., 1983) ear canal collapse due to pressure of the earphone on the pinna (Ventry et al., 1961; Chandler, 1964; Chaiklin and McClellan, 1971) earphone/bone-vibrator placement (Villchur, 1970) and non-organic hearing loss.

We do not believe that either patient had non-organic hearing loss, as neither complained of any impairment. Patient 1 was referred for management of tinnitus and Patient 2 for further investigation of an audiogram suggestive of noise-induced hearing loss, of which he was unaware prior to testing. It also seems unlikely that insertion of the speculum in each case would reverse their apparent hearing losses if they truly had non-organic hearing loss. Neither does the conductive hearing loss appear to be due to partial ossicular dislocation, although Patient 2's head injury could have caused such pathology. Such a diagnosis is consistent with preservation of the stapedial reflexes (Klockhoff, 1961; Anderson and Bar, 1971) but one would usually (though not always) expect to see hypermobility of the drum on tympanometry, and there would be no reason to expect improvement in hearing with plastic inserts in the ear canals.

The precise positioning of earphones on the head - quite apart from the possibility of their provoking ear canal collapse - can lead to threshold inaccuracies at both high and low frequencies. If the entire system, from sound source to eardrum, is not airtight, which in turn will depend on the inter-relationship between headset force and head size (Erber, 1968), then leakage of low frequency sound may occur (Zwislocki et al., 1988). Although this effect has been shown experimentally (Burkhard and Corliss, 1954), its effect on pure tone thresholds has not been quantified clinically. The ISO standard (1988) merely specifies the headband force on the basis of an 'average' head width of

TABLE I

THE AVERAGE CHANGE IN HEARING THRESHOLD AT EACH FREQUENCY ON INSERTION OF AN EAR CANAL SPECULUM IN 10 PATIENTS WITH NO EVIDENCE OF EAR CANAL COLLAPSE

\begin{tabular}{ccccccccc}
\hline $\mathrm{kHz}$ & 0.25 & 0.5 & 1 & 2 & 3 & 4 & 6 & 8 \\
$\mathrm{~dB}$ & -2.8 & -0.6 & +1.9 & -0.3 & -0.6 & +2.8 & -1.9 & -3.8 \\
\hline
\end{tabular}

$(+)=$ improvement in threshold; $(-)=$ deterioration in threshold. 
$145 \mathrm{~mm}$. At higher frequencies, leakage of sound is not as important a factor but the precise configuration of the cavity created by the earphone and the external ear (which may alter in the same subject with changes in earphone placement or between subjects with different external ear shapes/sizes) influences the sound pressure at the level of the eardrum (Erber, 1968; Villchur, 1970; Zwislocki et al., 1988). Thus headset force, head size, earphone placement and external ear shape and size can affect air conduction thresholds. The variability of our patients' audiograms could be explained by alterations in headset force or earphone placement. However, particularly in Patient 1, on whom two audiograms were carried out in quick succession, it appears improbable that simultaneously, the pressure of the earphone varied over a period of minutes (to account for the improved low frequency thresholds) and that the site of placement of the earphones (to improve the high frequency thresholds) was optimized. It is more likely that the plastic insert negated the effect of ear canal collapse and reversed the apparent conductive loss in this way. The clinical finding of a narrow ear canal on that side further supports this view.

It could also be suggested that the improvement in thresholds observed with a speculum in situ merely reflects alterations in the resonant characteristics of the external ear canal brought about by the presence of a foreign object in the canal. While we cannot totally exclude such a possibility from our findings in the ten patients reported above, it would seem to be an improbable explanation. In these patients a change in threshold of greater than $15 \mathrm{~dB}$ was never observed and in those cases where discrepancies of $10 \mathrm{~dB}$ or $15 \mathrm{~dB}$ were observed, the changes were never seen at two adjacent frequencies. In addition, only one ear in which a $15 \mathrm{~dB}$ change was seen, did this change represent an improvement in threshold.

The two patients reported serve to highlight several important implications of ear canal collapse. The apparent high frequency loss - usually in older patients - may be presumed to be a recruiting sensorineural loss. Bone conduction testing is often overlooked, particularly as tympanometry and stapedial reflexes are normal. Patient l's situation was further compounded as the loss was asymmetrical and apparently progressive suggestive of sinister retrocochlear pathology. Multiple investigations were instituted - many of which were expensive and time consuming, not to mention the anxiety caused to the patient. Bone conduction thresholds on the first visit would have helped clarify the true nature of the loss.

Patient 2's audiogram was misinterpreted elsewhere as being suggestive of noise-induced-hearing-loss. This pitfall was previously highlighted by Coles (1967), and could have medicolegal and economic implications for both employee and employer, as well as influencing subsequent career prospects of the employee. His previous mastoid surgery may have caused damage to the ear canal and predisposed him to such collapse.

In order to avoid threshold inaccuracies due to ear canal collapse, several measures have been recommended. Pearlman (1975) suggested otoscopic examination prior to audiometry in order to identify narrow (i.e. 'at risk') or already collapsed ear canals and observation of the effect on canal patency of pressing the pinna against the head, i.e. to simulate earphone pressure, while observing canal size otoscopically.

Alternatively, circumaural earphones which rest on the skull rather than on the pinna (Marshall and Grossman, 1982), and insert earphones help prevent collapse, but have other problems such as difficulty with calibration, limitation of high frequency response and hygiene (reviewed in detail by Zwislocki et al., 1988 and Killion and Villchur, 1989). The supra-aural earphone (TDH-39 with MX-41/AR cushions) used in our testing is the standard type of earphone employed for routine audiometric testing in sound-proof booths, and has the advantage of being easily calibrated, but, however, rests on the pinna and will make ear canal collapse more likely in a susceptible patient.

A third strategy which has been used by other authors, and indeed in our patients, is the placement of an insert of various kinds into the ear canal to maintain its patency (Ventry et al., 1961; Coles, 1967; Pearlman, 1975; Penrod, 1981; Marshall and Grossman, 1982). Although this procedure may produce small errors due to changes in ear canal resonance as discussed above, the magnitude of such errors is unlikely to be such as to mask the advantage of keeping the canal patent.

In addition to the possible misdiagnoses caused by failure to identify the true nature of an apparent high frequency hearing loss highlighted above, other problems may arise. Amplification may be advised inappropriately or unnecessary surgical exploration of the middle ear undertaken. The clinician/audiologist needs to be aware of this possible error in audiometry and compensate for it by one of the methods outlined above.

\section{References}

Anderson, H., Barr, B. (1971) Conductive high-tone hearing loss. Archives of Otolaryngology 93: 599-605.

Bess, J. C. (1971) Ear canal collapse. A review. Archives of Otolaryngology 93: 408-412.

British Standards Institution (1988) I.S.O. 389 - Part 5. Standard reference zero for the calibration of pure tone air conduction audiometers. Specification for a standard reference zero using an acoustic coupler complying with BS 4668.

Bryde, R. L., Feldman, A. S. (1980) An approach to the management of the collapsing ear canal. ASHA 22: 734 .

Burkhard, M. D., Corliss, E. L. R. (1954) The response of earphones in ears and couplers. Journal of the Acoustical Society of America 26(5): 679-685.

Chaiklin, J. B., McClellan, M. E. (1971) Audiometric management of collapsible ear canals. Archives of Otolaryngology 93: $397-407$.

Chandler, J. R. (1964) Partial occlusion of the external auditory meatus: Its effect upon air and bone conduction acuity. Laryngoscope 74: 22-54.

Coles, R. A. (1967) External meatus closure by audiometer earphone. Journal of Speech and Hearing Disorders 32: 296-297.

Creston, J. E. (1965) Collapse of the ear canal during routine audiometry. Journal of Laryngology 79: 893-901.

Creston, J. E., Tice, R. E. (1964) Collapse of the ear canal during audiometry. Archives of Otolaryngology 79: 389-392.

Dick, J. C. (1947) Observations on the elastic tissue of the skin with a note on the reticular layer at the junction of the dermis and epidermis. Journal of Anatomy 81: 201-211.

Erber, N. P. (1968) Variables that influence sound pressures generated in the ear canal by an audiometric earphone. Journal of the Acoustical Society of America 44(2): 555-562.

Hildyard, V. H., Valentine, M. A. (1962) Collapse of the ear canal during audiometry. Archives of Otolaryngology 75: 422-423.

Killion, M. C., Villchur, E. (1989) Comments on 'Earphones in audiometry' (Zwislocki et al., Journal of the Acoustical Society of America 83: 1688-1689 (1988)). Journal of the Acoustical Society of America 85(4): 1775-1779.

Klockhoff, I. (1961) Middle ear muscle reflexes in man. Acta Otolaryngologica (suppl 164): 1-92.

Ma, C. K., Cowdry, E. V. (1950) Aging of elastic tissue in human skin. Journal of Gerontology 5: 203-210.

Marshall, L., Grossman, M. A. (1982) Management of earcanal collapse. Archives of Otolaryngology 108: 357-361. 
Marshall, L., Martinez, S. A., Schlaman, M. E. (1983) Reassessment of high-frequency air-bone gaps in older adults. Archives of Otolaryngology 109: 601-606.

Mustain, W. D., Hasseltine, H. E. (1981) High frequency conductive hearing loss. A case presentation. Laryngoscope 91: 599-604.

Pearlman, R. C. (1975) Preventing collapse of external auditory meatus during audiometry. Archives of Otolaryngology 101: 686-688.

Penrod, J. P. (1981) Ear canal collapse: A case presentation. Ear and Hearing 2: 88-89.

Randolph, L. J., Schow, R. L. (1983) Threshold inaccuracies in an elderly clinical population: Ear canal collapse as a possible cause. Journal of Speech and Hearing Research 26: 54-58.

Shipton, M. S. (1979) Tables relating pure-tone audiometric threshold to age. National Physical Laboratory Acoustics Report 94.
Ventry, I. M., Chaiklin, J. B., Boyle, W. F. (1961) Collapse of the ear canal during audiometry. Archives of Otolaryngol ogy 73: 727-731.

Villchur, E. (1970) Audiometer-earphone mounting to improve intersubject and cushion-fit reliability. Journal of the Acoustical Society of America 48: 1387-1396.

Zwislocki, J., Kruger, B., Miller, J. D., Niemoeller, A. F., Shaw, E. A., Studebaker, G. (1988) Earphones in audiometry. Journal of Acoustical Society of America 83: 1688-1689.

Address for correspondence:

Dr Cliodna F. O Mahoney,

Dept of Audiological Medicine,

Royal National Throat, Nose and Ear Hospital,

330 Gray's Inn Road,

London WC1X 8DA. 